\title{
2. Cinquenta anos depois de $O$ segundo sexo, a quantas anda o feminismo na França?: uma entrevista com Michelle Perrot
}

\author{
Ingrid Galster
}

Universität Paderborn, Alemanha

Copyright $(2) 2003$ by Lendemains, Tübingen, Stauffenburg Verlag, 1999, n. 94, p. 84-91. Traduzida e publicada com permissão da autora e da Editora.

\footnotetext{
* A entrevista foi realizada por escrito. Enviei minhas questões em fevereiro de 1999 e recebi as respostas em julho de 1999. (Observação da editoria: esta nota, no original e na tradução de Eleonora Castelli para o português, comporta também dados biográficos de Michelle Perrot, dados esses que são suprimidos aqui por já constarem na apresentação de Joana Pedro.)
}

Ingrid Galster*: Michelle Perrot, desde o começo do movimento feminista na França nos anos 1970, você refletiu, com outras historiadoras e historiadores, sobre a possibilidade de uma história das mulheres, reflexão que resultou, notadamente, em uma obra em cinco volumes, publicada no começo dos anos 1990 e traduzida em 11 línguas. Você teve muitas alunas que hoje trabalham sob essa ótica, dentre as quais muitas ocupando postos na universidade francesa. No exterior, não é talvez muito sabido que você também intervém no debate feminista e que você informou, através de estudos panorâmicos, um público não especialista sobre o estado atual da questão. Cinqüenta anos depois da publicação do Segundo sexo, a quantas anda, em sua opinião, o feminismo na França?

Michelle Perrot: O feminismo francês é paradoxal. Sua influência é relativamente forte; suas estruturas são fracas, característica antiga que perdura e que coloca a questão de seu modo de ação. Conta-se um pequeno número de associações feministas: uma dúzia, talvez. Da época heróica dos anos 1970-75, resta apenas Choisir, graças a Gisèle Halimi. Dialogues de Femmes acabou de se dissolver depois de 20 anos de debates mensais (Alice Colanis). Sem voltar tanto no tempo, a maior parte das associações criadas para promover a paridade se dissolveu, estimando ter cumprido sua missão após a revisão constitucional; exceção feita à Assemblée des Femmes (de cunho socialista, Ivette Roudy), que organiza há quatro anos uma universidade de verão. 
1 Coordenação Nacional das Associações pelo Direito ao Aborto e à Contracepção.

${ }^{2} \mathrm{O}$ nome dessa associação faz alusão à revista mensal MarieClaire, destinada às mulheres.

3 Associação das Mulheres Diplomadas das Universidades, fundada por volta de 1920.
Poderíamos, no entanto, citar a CADAC, ${ }^{1}$ as Marie pas Claires, ${ }^{2}$ a Associação das Mulheres Jornalistas, que tem uma campanha vigorosa contra o sexismo na imprensa e na publicidade, atribuindo todos os anos um prêmio para a publicidade menos sexista, a Rede pela Memória das Mulheres, que se preocupa com a maneira de rememorar o lugar das mulheres na cidade e na cronologia, etc. Existem também associações mais antigas, que têm uma atuação bem feminista: é o caso da $\mathrm{AFDU},{ }^{3}$ que se preocupa atualmente com as desigualdades nos setores científicos e com os efeitos perversos da mescla, etc... Sem contar as associações locais.

O feminismo inspira diversas revistas: Nouvelles Questions Féministes (Christine Delphy), os Cahiers du GRIF (Françoise Collin), Clio, revista fundada em 1995 por historiadoras, Lunes (ano 1, número 1, 1997), rica em informações de todos os tipos, etc.

O feminismo inspira também numerosos colóquios, científicos ou políticos, como o de janeiro de 1999 em razão do cinqüentenário do Segundo sexo. No dia 8 de março, todos os anos - e foi particularmente verdade em 1999 -, ocorrem colóquios, debates ou conferências sobre temas relacionados a "mulheres". Assim foi em Mans sobre "mulheres e paz", em Rouen sobre "mulheres e o segundo milênio", etc. Essas ocasiões reúnem geralmente um público numeroso.

O feminismo, enfim, é capaz de suscitar mobilizações pontuais: assim foi em novembro de 1995, a manifestação de mais ou menos 30.000 mulheres em Paris, onde se viu retrospectivamente um sinal precursor dos movimentos sociais de dezembro. Recentemente as feministas organizaram o boicote às Galerias Lafayette, que, para apresentar a lingerie de Chantal Thomas, haviam montado vitrines com manequins vivos, projeto ao qual tiveram de renunciar. Isso ilustra o modo de existência do feminismo atual: vigilante, ocasional, latente.

Mas a ação mais importante dos últimos anos foi a do movimento pela paridade (1990 em diante), que ocasionou um verdadeiro debate na classe política, na sociedade e no próprio feminismo. Esse movimento teve como conseqüência, depois de debates parlamentares, uma modificação da Constituição. Um Observador da paridade existe hoje para prever as medidas suscetíveis de concretizar a paridade.

Dessa forma o feminismo, apesar de sua fraqueza organizacional, de uma certa dificuldade de transmissão na nova geração ("eu não sou feminista, mas...", dizem as jovens de menos de 30 anos), não deixa de ser uma força 
${ }^{4}$ Conforme a tentativa recente de descrever a situação: Ingrid GALSTER, 1999. latente, suscetível de modificações eventuais, e uma aspiração que contribuiu para a transformação e debate na sociedade francesa.

IG: Muitas igualitaristas, seguindo Beauvoir, se dão conta hoje de que o universalismo é um mito, pois ele tolerou, na verdade, a exclusão das mulheres na política. As feministas da diferença reivindicam, segundo as igualitaristas, o que Ihes é imposto. As desconstrucionistas em busca do feminino reprimido podem finalmente passar sem mulheres reais, porque o retorno do reprimido se manifesta também, se não mais, nos homens. ${ }^{4}$ Os diferentes paradigmas encontramse em uma aporia?

MP: O feminismo igualitarista e universalista - estilo Simone de Beauvoir - resta, me parece, majoritário na França. Mas as igualitaristas denunciam muito mais vigorosamente as armadilhas do universal tal qual ele foi construído. No entanto, elas não o questionam por causa disso. Isso foi visto quando do debate sobre a paridade, em que as universalistas se dividiram. Enquanto uma parte delas (Elisabeth Badinter, Danielle Sallenave, Elisabeth Roudinesco, Evelyne Pisier, etc.) recusava a paridade como sendo contrária ao individualismo universal, uma larga fração das outras defendia a paridade como medida para conduzir ao universal, que todavia continua sendo um objetivo, não uma realidade.

As feministas da diferença estavam sem dúvida mais à vontade, visto que podiam reivindicar a paridade em nome dessa própria diferença, em nome de um "nós, mulheres", capaz de renovar a aproximação da política. Essas "diferencialistas" também se dividem em duas correntes: as que falam de dois sexos radicalmente diferentes (conforme Antoinette Fouque, há dois sexos); as que falam de dois gêneros produzidos pela cultura e pela história. A prática produz diferença, uma diferença que as mulheres podem introduzir no campo político, não porque elas são mulheres, mas porque elas existem como mulheres.

No meio feminista francês o desconstrucionismo é muito menos importante.

O debate sobre a paridade confundiu os argumentos. Ele mostrou que era urgente, neste fim de século, retomar a questão da diferença de sexos, sob a luz da reflexão antropológica (Françoise Héritier, Masculin/ Féminin. La pensée de la différence, Odile Jacob, 1996), filosófica (Geneviève Fraisse, De la différence des sexes, PUF, 1996), psicanalítica, biológica e necessariamente histórica.

Há um desejo de reexaminar a questão em detalhes para fazer o inventário das teorias e tentar clarear as coisas. 
IG: Nos anos 1980, as teorias feministas parisienses tiveram uma grande repercussão nos Estados Unidos. Para ser mais precisa, identificou-se o French Feminism nas obras de Hélène Cixous, de Luce Irigaray e de Julia Kristeva. Você tem uma explicação para esse pars pro toto errôneo?

MP: Essa assimilação do French Feminism unicamente ao feminismo da diferença é na verdade chocante e sempre surpreendeu as feministas francesas que, majoritariamente, se insurgiam contra essa corrente. Às vezes violentamente, como nas batalhas dos anos 1970 em torno da sigla MLS (Mouvement de Libération des Femmes) entre Psych e Po (Psicanálise e Política, de Antoinette Fouque) e na maioria das outras. Mas isso parece agora irrisório.

Há verdadeiras razões para tal assimilação. Primeiramente, o verdadeiro talento de escrever das protagonistas (aliás, bastante diferentes uma das outras), que produziram obras novas e fortes no começo dos anos 1960, anos estes que viram justamente a grande ascensão do Movimento de Liberação das Mulheres. Tais obras pareceram inspirar esse movimento, o que na verdade não aconteceu.

Em seguida, o seu alcance internacional, ligado a sua posição no campo intelectual: especialista em literatura anglo-americana (ela trabalhou com Joyce), Cixous já era há muito tempo habituée dos Estados Unidos e da reflexão americana. Ela estava seguindo suas mesmas variações. Kristeva, por causa do grupo e da revista Tel Quel, por causa de Philippe Sollers, seu marido, pertencia a esses novos "mandarins", esses "samurais" que ela mesma descreveu em um romance/narrativa que leva esse título. Eu conheço menos as relações de Luce Irigaray.

Têm também forte importância as ligações com a psicanálise, dirigidas por Irigagay e Kristeva, mas mediatizadas por Cixous. É o apogeu de Lacan, e essas mulheres constituem a versão feminina que Antoinette Fouque, com Psych e Po e a famosa Livraria das Mulheres, aspirava reunir. Havia aí um pólo forte, visível, cuja linguagem coincidia com as lutas das mulheres, baseadas no corpo, o corpo enfim glorificado (o que não ocorre em Beauvoir), fundamento de uma cultura da diferença, do feminino. Suas obras, sua escrita, sua linguagem correspondem a uma real necessidade de uma orgulhosa afirmação de si.

Acrescentemos que não há, então, nada comparável nas outras disciplinas, nem em Antropologia, nem em História. Não há uma História das Mulheres digna desse nome. 
Eu acrescentaria, ainda, que as/os americanas/os encontravam ali o que elas/eles tinham vontade de encontrar: a expressão de uma expressão radical, suscetível de fundar uma separação de gênero, um eventual comunitarismo.

Coloco essas respostas a título de hipótese. Há aí um verdadeiro capítulo da história intelectual a ser desenvolvido.

IG: Hoje parece que não é mais na França, porém nos Estados Unidos, que se desenvolve a teoria feminista. Estou pensando sobretudo na atenção que suscitam os escritos de Judith Butler, que se alimenta muito, ressalte-se, da teoria francesa, mas que chega, no entanto, a uma posição original. Existem ainda pesquisas no plano teórico no feminismo francês?

MP: No plano teórico, sem dúvida alguma, elas não têm a intensidade da produção americana. Isso se deve, em parte, a razões institucionais. Nós não temos aqui nada que se compare aos Women's Studies e aos Gender Studies.

No entanto, a pesquisa está longe de ser negligenciada. $O$ diferencialismo está em nítido recuo. Ele acompanha a profunda crise da psicanálise. As teses da "escrita feminina" não têm mais validade. Nathalie Sarraute, reivindicada na escrita feminina, negou-a há muito tempo. Recentemente, Monique Wittig, agora instalada nos Estados Unidos, uma das figuras em voga desse pensamento, fez o mesmo. "Não há literatura feminina; para mim isso não existe. Na literatura, eu não separo as mulheres dos homens. Você é escritor ou não", dizia ela em uma entrevista ao Libération, em 17 de junho de 1989, quando recusa, aliás, toda idéia de uma natureza feminina ou sexuada e toma distância do direito à diferença. "É necessário abandonar o ponto de vista normal, ir além das categorias de sexo." Isso significa, de uma certa maneira, dizer não ao "sexo-rei" dos anos 1970-80. Na verdade, se Nathalie Sarraute e Monique Wittig contestam as convenções da linguagem e refletem sobre a influência da diferença dos sexos na escrita, elas nunca foram adeptas da "escrita feminina". Françoise Armengaud

${ }^{5}$ Françoise ARMENGAUD, 1998.

- Conforme Michelle PERROT, 1998, p. 413-424. faz bem em destacar isso. ${ }^{5}$ Se elas foram colocadas nessa linha, isso ocorreu, sem dúvida alguma, involuntariamente.

Há algo comparável aqui. As pesquisas mais importantes se fazem no âmbito das ciências sociais: Sociologia (conforme a revista do MAGE, Travail, Genre et Sociétés, n. 1, 1999), Antropologia (conforme Françoise Héritier, Masculin/Féminin: la pensée de la différence, Odile Jacob, 1996; Nicole-Claude Mathieu, etc.), História. A História das Mulheres não é em si uma teoria, mas se baseia em princípios teóricos, sendo os principais deles fornecidos por Michel Foucault, ${ }^{6}$ notadamente a noção de historicidade. 
${ }^{7}$ Conforme LE DÉBAT, 1995.

No que diz respeito às filósofas, citarei os textos de Geneviève Fraisse (La différence des sexes, PUF, 1996; Les femmes et leur histoire, Gallimard, 1998) e Françoise Collin, fundadora dos Cahiers du GRIF, cuja última obra, Je partirais d'um mot: le chap symbolique (Fus Art, 1999, coletânea de artigos), me parece a contribuição mais inteligente para 0 pensamento sobre o feminismo contemporâneo. Ela mesma se situa decididamente na vertente anti-essencialista, mas convida também a que se ultrapasse esse debate.

IG: As relações entre a França e os Estados Unidos, no que diz respeito ao feminismo, são marcadas pelo malentendido e pela ignorância. Já falei do French Feminism, que, para os americanos, reúne somente feministas da diferença. Por outro lado, a discussão decorrente da publicação do livro de Mona Ozouf, Les Mots des Femmes, em 1995, ${ }^{7}$ mostrou que as feministas americanas não são muito conhecidas na França, até mesmo Judith Butler, que, na Alemanha, conhece um grande sucesso. Pode-se explicar esses mal-entendidos e o fato de que as feministas francesas se mantêm em um círculo fechado?

MP: Há, de fato, na sociedade francesa em geral e em certos meios intelectuais freqüentemente à esquerda, um anti-americanismo estupeficante que, em nome de uma incrível boa consciência da superioridade francesa, conduz a uma cegueira muito danosa. As feministas francesas são provavelmente as mais abertas para a reflexão americana, em razão de seus contatos desde o começo com o Women's Lib. Nós nos apropriamos muito cedo dessa produção, sobretudo em história, onde mulheres como Natalie Zemon Davis, Joan Scott (Gender and the Politics of History faz parte dos nossos clássicos), Karroll Smith-Rosemberg, Claudia Koonz, etc. são muito lidas. O livro de Mona Ozouf não exprime a posição das feministas francesas, mas tende curiosamente (visto que a autora conhece bem os Estados Unidos) a exprimir uma certa "diabolização" do feminismo americano, que encontramos de maneira bastante corrente, por exemplo, na obra de Gilles Lipovetsky. Tratase também, para este autor, de uma maneira de caricaturar o feminismo em geral.

As feministas francesas mantêm-se, sem dúvida, excessivamente em "seu círculo fechado", é verdade. No entanto, nesse caso, elas seriam certamente uma brecha em direção a um feminismo americano com o qual elas se sentem, na maior parte do tempo, solidárias.

IG: Nestes últimos tempos, dois livros de autores masculinos sobre temas feministas fizeram bastante barulho: primeiramente, La troisième femme, do filósofo nascido em 
${ }^{8}$ Michelle PERROT, Yves SINTOMER, Beate KRAIS e Marie DURU-BELLAT, 1999.

${ }^{9}$ Conforme Ingrid GALSTER, 1998.

${ }^{10}$ Christophe CHARLE, 1999.
Grenoble, Gilles Lipovetsky, que você acabou de mencionar; em seguida, La domination masculine, de Pierre Bourdieu. Como você julga o fato de os homens tratarem do feminismo?

MP: Se os intelectuais masculinos franceses tratam do feminismo, é, sem dúvida, porque é importante, é sinal de seu desenvolvimento e de seu papel no espaço público. Uma forma de reconhecimento. O sucesso dessas duas obras é, aliás, a melhor prova da "dominação masculina" no campo intelectual: as mulheres têm sempre mais dificuldade para se fazer ouvir. Isso posto, ambos os livros, que tive a ocasião de criticar (um no Nouvel Observateur, o outro no Libération e no número 1 da Revue du Mage), ${ }^{8}$ mostram sobretudo a grande ignorância que esses autores, desigualmente prestigiosos, têm do feminismo em geral e do feminismo francês em particular. Pierre Bourdieu, que cita Butler, Mackinnon etc., parece ignorar uma grande parte da pesquisa feminista francesa da qual ele não tem, a priori, uma opinião muito boa. Dominadas, as mulheres podem pensar sua dominação? É uma questão que ele mesmo colocou.

IG: Se as francesas estão, contrariamente às alemãs, relativamente presentes no ensino superior, ${ }^{9}$ elas continuam a ser fortemente excluídas do parlamento. Assim, não é de se surpreender que o debate dos anos 1990 tenha sido dominado na França - você já falou disso - pelo tema da paridade, que é bastante controverso. Os diferencialistas são a favor, a fim de permitir que as mulheres façam a sociedade aproveitar as supostas qualidades femininas. As igualitaristas estão divididas: algumas são absolutamente contra porque temem um sexismo ao contrário; outras prevêem que, sem reformas, a igualdade abstrata continuará excluindo as mulheres da política. Em todo caso, Lionel Jospin pediu que se colocasse o princípio da paridade na Constituição. O que você pensa disso?

MP: Você tem razão. As francesas estão relativamente presentes no ensino superior, com grandes desigualdades setoriais, como aponta o recente estudo de Christophe Charle. ${ }^{10} \mathrm{Em} \mathrm{1992,} \mathrm{a} \mathrm{taxa} \mathrm{de} \mathrm{feminização} \mathrm{do} \mathrm{quadro} \mathrm{de}$ professores era de $28 \%$; em Letras, as mulheres constituíam $23 \%$ do corpo de professores, e $41 \%$ dos "mestres de conferência", mas somente $8 \%$ e $27 \%$ em Ciências.

Na política a presença feminina é bem menor, visto que há somente $6 \%$ de mulheres deputadas (eleições de 1997). Esse atraso político, que beira à exclusão, é uma especificidade francesa que não vem de hoje, dado que o 
11 Elisabeth BADINTER et al., 1999: encontramos nessa obra diversas contribuições dos anti-paritários. Para uma exposição histórica mais abrangente, e em um sentido favorável à paridade, conforme Janine MOSSUZ-LAVAU, 1998. Conforme também Béatrice DURAND, 1998.

12 Pour une démocratie paritaire, 1993. país da Declaração dos Direitos dos Homens demorou muito a conceder o direito de voto para as mulheres (em 1944 somente). Daí a existência da crítica do universal e da reivindicação paritária, vinda, na verdade e primeiramente, das instituições européias, mas expressadas fortemente no livro de Françoise Gaspard, Anne Le Gall e Claude ServanSchreiber, Aux armes citoyennes (Le Seuil, 1992). Elas não expunham nenhum argumento diferencialista, mas somente o direito, e defendiam a paridade para chegar à igualdade. Acredito que muitas mulheres entenderam, e ainda entendem assim. Foi o manifesto das dez ex-ministras, no Express, que complicou as coisas ao dizer que as mulheres, por causa de sua feminilidade, modificariam as práticas da política. Um pouco mais tarde, o livro de Sylviane Agacinski, esposa do Primeiro Ministro, foi no mesmo sentido. Isso provocou a reação hostil das "universalistas", encabeçadas por Elisabeth Badinter, ${ }^{11}$ e também debates que despertaram a reflexão sobre cidadania e o lugar das mulheres na sociedade. A reivindicação paritária é majoritária (qual partido poderia se opor a isso?) e popular na opinião pública.

No que me diz respeito, desde o começo tomei partido pela paridade, assinei o manifesto das $577,{ }^{12}$ escrevi no Le Monde defendendo a idéia de uma "paridade universalista". O universal é um objetivo, não uma realidade, e a paridade é um meio de chegar lá. É por isso que me alegro muito com a modificação operada recentemente na Constituição. Faço parte do Observatório da Paridade, do qual Dominique Gillot (deputada socialista) é relatora, e que tem por objetivo propor medidas concretas para realizar essa paridade política e estimular a paridade em todos os âmbitos.

\section{Referências bibliográficas}

ARMENGAUD, Françoise. "Sarraute et Wittig: la contestation des conventions du discours". Nouvelles Questions Féministes, v. 19, n. 1, p. 35-64, 1998.

BADINTER, Elisabeth et al. Le piège de la parité. Hachette Littératures: Paris, 1999.

CHARLE, Christophe "Les femmes dans l'enseignement supérieur: dynamiques et freins d'une présence, 19461992". In: DUCLERT, Vincent; FABRE, Rémi; FRIDENSON, Patrick (eds.). Avenirs et avant-gardes en France, XIXe Xxe siècles, Hommage à Madeleine Rebérioux. La Découverte: Paris, 1999. p. 84-105.

DURAND, Béatrice. "La parité, entre nature et culture". Lendemains, n. 91/92, p. 115-125, 1998.

GALSTER, Ingrid. "Positionen des Französischen Feminismus". In: GNÜG, Hiltrud; MÖHRMANN, Renate (eds.). Frauen 
Literatur Geschichte. Schreibende Frauen vom Mittelalter bis zur Gegenwart. Stuttgart: Metzler-Verlag, 1999, p. 591602.

. Relato do colóquio "Les femmes et les sciences en France et en Allemagne" (Université de la Sarre, 5 jun. 1998), publicado no Frankfurter Allgemeine Zeitung, 24 jun. 1998.

LE DÉBAT. n. 87, nov.-déc. 1995.

MOSSUZ-LAVAU, Janine. Femmes/Hommes pour la Parité. Presses de Sciences Po: Paris, 1998.

PERROT, Michelle. "Michel Foucault et l'histoire des femmes". In: Les femmes ou les silences de l'Histoire. Flammarion: Paris, 1998. p. 413-424.

PERROT, Michelle; SINTOMER, Yves; KRAIS, Beate; DURU-BELLAT, Marie. "Controverses: La domination masculine de Pierre Bourdieu, lu par Michelle Perrot, Yves Sintomer, Beate Krais, Marie Duru-Bellat. Réponse de Pierre Bourdieu". Travail, Genre et Société: la revue du MAGE, n. 1, p. 203-234, 1999.

POUR UNE DÉMOCRATIE PARITAIRE. Le Monde, 10 nov. 1993.

Tradução de Eleonora Castelli 